\title{
Serum concentrations of chorionic gonadotrophin, oestradiol-17 $\beta$ and progesterone during early pregnancy in the south Indian bonnet monkey (Macaca radiata)
}

\author{
A. Jagannadha Rao, S. G. Kotagi and N. R. Moudgal \\ Center for Advanced Study in Reproductive Biology (ICMR), Department of Biochemistry, \\ Indian Institute of Science, Bangalore-560 012, India
}

\begin{abstract}
Summary. Serum concentrations of chorionic gonadotrophin (CG) during early pregnancy in the bonnet monkey (Macaca radiata), were determined by a radioimmunoassay validated for measuring monkey chorionic gonadotrophin. The earliest time at which CG could be detected was on the 28 th day of a fertile cycle and it could not be detected beyond the 50th day. During a fertile cycle, mean values of oestradiol-17 $\beta$, in addition to exhibiting a preovulatory peak around Days 9-10 of cycle, exhibited a secondary peak around Day 30 of the cycle. Serum progesterone: levels remained elevated throughout the period of study from Day 18 to Day 50 and at no time did the levels fall below $2 \mathrm{ng} / \mathrm{ml}$.
\end{abstract}

\section{Introduction}

Although rhesus monkeys ( Macaca mulatta) have been frequently used to investigate problems of primate reproductive physiology, these monkeys are difficult and expensive to obtain and are not very suitable for studying events associated with implantation and late pregnancy (Stabenfeldt \& Hendrickx, 1973). Over the past few years we have been using the south Indian bonnet monkey ( Macaca radiata) as an experimental animal to investigate the role of $\mathrm{LH}$ and FSH in the regulation of gonadal function (Mukku \& Moudgal, 1979; Murty, Sheela Rani, Moudgal \& Prasad, 1979). As a prelude to undertaking detailed studies on implantation and regulation of chorionic gonadotrophin (CG) secretion in the bonnet monkey, we have measured the concentrations of serum progesterone, oestradiol-17 $\beta$ and chorionic gonadotrophin during early pregnancy.

\section{Materials and Methods}

\section{Animals}

Adult cyclic females weighing 5-6 kg were recruited from the stock colony maintained at the Indian Institute of Science. The husbandry was as previously described (Prahalada, Mukku, Rao \& Moudgal, 1975; Mukku, Prahalada \& Moudgal, 1976) and the day on which vaginal bleeding was first noticed was considered as Day 1 of the cycle. Blood samples were collected between $09: 00$ and $11: 00 \mathrm{~h}$ on the days specified: anaesthesia was not used. Serum was separated within $24 \mathrm{~h}$ and the samples stored at $-20^{\circ} \mathrm{C}$ until further processing.

Female bonnet monkeys were housed in the cage of selected proven males from Day 9 until Day 14 of the menstrual cycle. Females of this colony exhibit peak values of serum oestradiol-17 $\beta$ on Day 9 or Day 10, the ovulatory surge of LH occurring within $24 \mathrm{~h}$ of this surge. All the serum 
samples collected on Days 9 and 10 were analysed for oestradiol-17ß and those on Day 18 for progesterone. In retrospect, the results of only those monkeys that exhibited normal cyclic levels on these days were considered for inclusion. Although the length of the follicular phase could be variable, for the sake of convenience Day 12 of the fertile cycle has been considered as Day 1 of pregnancy in this study.

\section{Hormones}

Highly purified human chorionic gonadotrophin (hCG) CR-123 (10 000-12 $000 \mathrm{i.u} / \mathrm{mg}$ ) was obtained as a gift from the NIAMDD, Bethesda, U.S.A. Ovine LH and its $\beta$ subunit were provided by Professor C. H. Li, Hormone Research Laboratory, University of California, San Francisco, U.S.A. and by Dr M. R. Sairam, Clinical Research Institute of Montreal, Canada. Tritiated progesterone (sp. act. $96 \mathrm{Ci} / \mathrm{mmol}$ ) and tritiated oestradiol $-17 \beta$ (sp. act. $100 \mathrm{Ci} / \mathrm{mmol}$ ) were obtained from Amersham International, U.K. Unlabelled steroids and steroid derivatives for conjugation with proteins were obtained from Steraloids, New Hampshire, U.S.A. All other chemicals used were of analytical grade, locally procured.

\section{Radioimmunoassays}

Chorionic gonadotrophin. Antiserum to highly purified ovine LH $\beta$ was raised in rabbits according to the procedure of Vaitukaitis, Robbins, Nieschlag \& Ross (1971). Each animal received a total of $1.5 \mathrm{mg}$ antigen over a period of 2 months, at the end of which they were test bled. Serum from individual animals was tested for its ability to bind to iodinated hCG and its crossreactivity with serum obtained from monkeys on Days 27-32 of the fertile cycle. Iodination of hCG (CR-123) was done using the chloramine-T method of Greenwood, Hunter \& Glover (1963). The specific activity of iodinated preparation ranged from 40 to $50 \mu \mathrm{Ci} / \mu \mathrm{g}$. Radioimmunoassay was carried out by incubating $100 \mu \mathrm{l}$ antiserum ( $1: 4000$ dilution) to ovine $\mathrm{LH} \beta$ from rabbit No. 17 with $100 \mu{ }^{125}$ I-labelled hCG (20000 c.p.m.; $0.5 \mathrm{ng} \mathrm{hCG}$ ) in the presence or absence of known quantities of unlabelled hCG or serum from pregnant monkeys in $3 \mathrm{ml}$ glass tubes. Bound and free radioactivity were separated using the double-antibody method and the radioactivity in the pellet was monitored in a Packard Gamma Spectrometer. A typical standard inhibition plot for hCG is shown in Text-fig. 1. The dose-response curve over the range 0.5 to $10 \mathrm{ng}$ was curvilinear, and the sensitivity of the assay was around $0.5 \mathrm{ng} /$ tube or $5 \mathrm{ng} / \mathrm{ml}$. Parallel inhibition curves could be obtained by using serum from pregnant monkeys (Text-fig. 1). Cross-reactivity of monkey pituitary LH was checked by using a monkey pituitary homogenate and serum from gonadectomized monkeys (Text-fig. 1). Monkey pituitary homogenate showed poor crossreactivity (non-parallel inhibition) and even to obtain this, a large volume of homogenate ( $300 \mu \mathrm{l}$, representing nearly one-third of a pituitary) had to be used. Serum from gonadectomized monkeys when used in $300 \mu$ lamounts did not show any significant inhibition. In contrast, serum from monkeys on Days 34-36 of the fertile cycle (Days 22-24 of gestation) sometimes had to be diluted before use to obtain values in the sensitive part of the standard plot ( $80-20 \%$ inhibition). Detection of chorionic gonadotrophin during the earlier parts (Days 28-30 and 50-62) of the fertile cycle, however, required 200-300 $\mu \mathrm{l}$ serum. To overcome possible interference due to the large quantities of sera used in the assay, routinely all assays were carried out using bovine serum as a diluent for standards. The intra- and inter-assay variations determined were $10.3 \%(n=6)$ and $18.5 \%(n=9)$ respectively.

Progesterone and oestradiol-17 $\beta$. Monkey serum $(0.1-0.5 \mathrm{ml})$ was extracted twice with $10 \mathrm{ml}$ diethyl ether by vortexing for $1 \mathrm{~min}$, the aqueous phase was frozen in liquid nitrogen and the organic phase was transferred to ether-washed dry tubes and allowed to evaporate at $40^{\circ} \mathrm{C}$. The residue was reconstituted in $0.1-0.5 \mathrm{ml}$ phosphate buffer $(0.01 \mathrm{M}) \mathrm{pH} 7.2$ containing $0.15 \mathrm{M}$-sodium chloride and $0 \cdot 2 \%$ gelatin (Difco Laboratories, Detroit, Michigan, U.S.A.) and volumes of 50, 100 


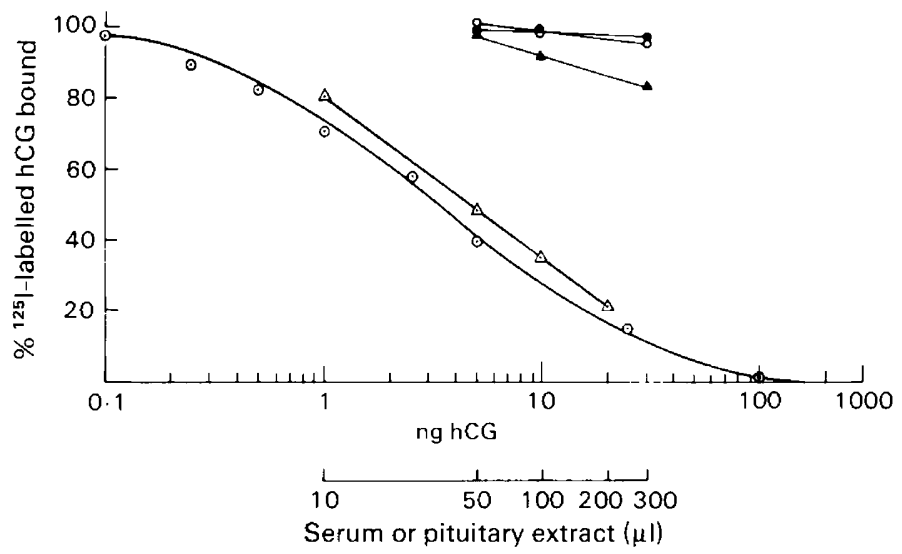

Text-fig. 1. Inhibition plot for hCG $(\odot-\odot)$, and different quantities of pregnant (Day 20) bonnet monkey serum $(\Delta-\Delta)$, bonnet monkey pituitary homogenate $(\boldsymbol{\Delta}-\mathbf{\Delta})$, and gonadectomized bonnet monkey $(-\mathrm{male}, \mathrm{O}-\mathrm{O}$ female) serum.

or $200 \mu \mathrm{l}$ were used for assay. Bound and free radioactive steroids were separated using dextran $\mathrm{T}$ 70 (Pharmacia, U.S.A.) (0.025\%) coated with charcoal $(0.25 \%)$. Radioactivity in the samples was monitored in a Rack Beta (LKB) counter using a toluene-Triton X-100 (2:1 v/v) mixture containing $0.75 \%$ PPO and $0.03 \%$ POPOP as scintillation fluid. The counting efficiency was $48.5 \%$. Extraction efficiency was determined by monitoring the recovery of labelled steroid ( $\sim 5000$ c.p.m.) added to serum samples before extraction and was determined in duplicate in each assay. Mean \pm s.e.m. percentage recovery was $82 \pm 4(n=16)$ for progesterone and $85 \pm 6(n=16)$ for oestradiol-17 $\beta$ and the results expressed are uncorrected for recovery.

The antiserum for the progesterone assay was raised in rabbits against progesterone-3(carboxymethyl) oxime-BSA conjugate and used at an initial dilution of 1:6000 at which it bound $30 \%$ of the tracer used. The antiserum showed a cross-reaction of $3.5 \%$ with $17 \alpha$-hydroxyprogesterone, $5 \%$ with $20 \alpha$-dihydroprogesterone, $1 \%$ with pregnenolone, $0.2 \%$ with testosterone and $0.01 \%$ with cortisol. The antiserum used for the oestradiol-17 $\beta$ assay was raised against oestradiol-17 $\beta$ hemisuccinate-BSA conjugate and was used at a dilution of $1: 7000$. The antiserum cross-reacted with other steroids to the following extent: oestriol $1 \%$, oestrone $10 \%$ and testosterone $1 \%$. The sensitivities of the assays were $20 \mathrm{pg}$ progesterone $/ \mathrm{ml}$ and for $10 \mathrm{pg}$ oestradiol $-17 \beta / \mathrm{ml}$. The interand intra-assay variations $(\%)$ were $10 \cdot 3(n=10)$ and $6.5(n=8)$ respectively for progesterone and $8 \cdot 66(n=9)$ and $5 \cdot 2(n=8)$ respectively for oestradiol-17 $\beta$. The values were analysed for statistical significance by Student's $t$ test.

\section{Results}

Although CG was detectable in some pregnant monkeys on Days 25-27 of the fertile cycle, CG could be detected with certainty only from Day 28 of the fertile cycle. In the absence of a monkey CG reference standard the CG values have been expressed in terms of hCG (CR-123) equivalents. Serum levels of CG ranged from $5 \mathrm{ng} / \mathrm{ml}$ at Day 28 to peak values of $700-1500 \mathrm{ng} / \mathrm{ml}$ about Day 35 of the fertile cycle (Text-fig. 2). The levels started decreasing by 38-39 days and fell to very low levels by about 50 days, after which they were not detectable even when 200-300 $\mu$ l of serum was used.

Although the oestrogen levels reported here are expressed in terms of oestradiol- $17 \beta$, it includes oestrone levels as the antiserum used cross-reacted with oestrone to the extent of $10 \%$. In addition to 


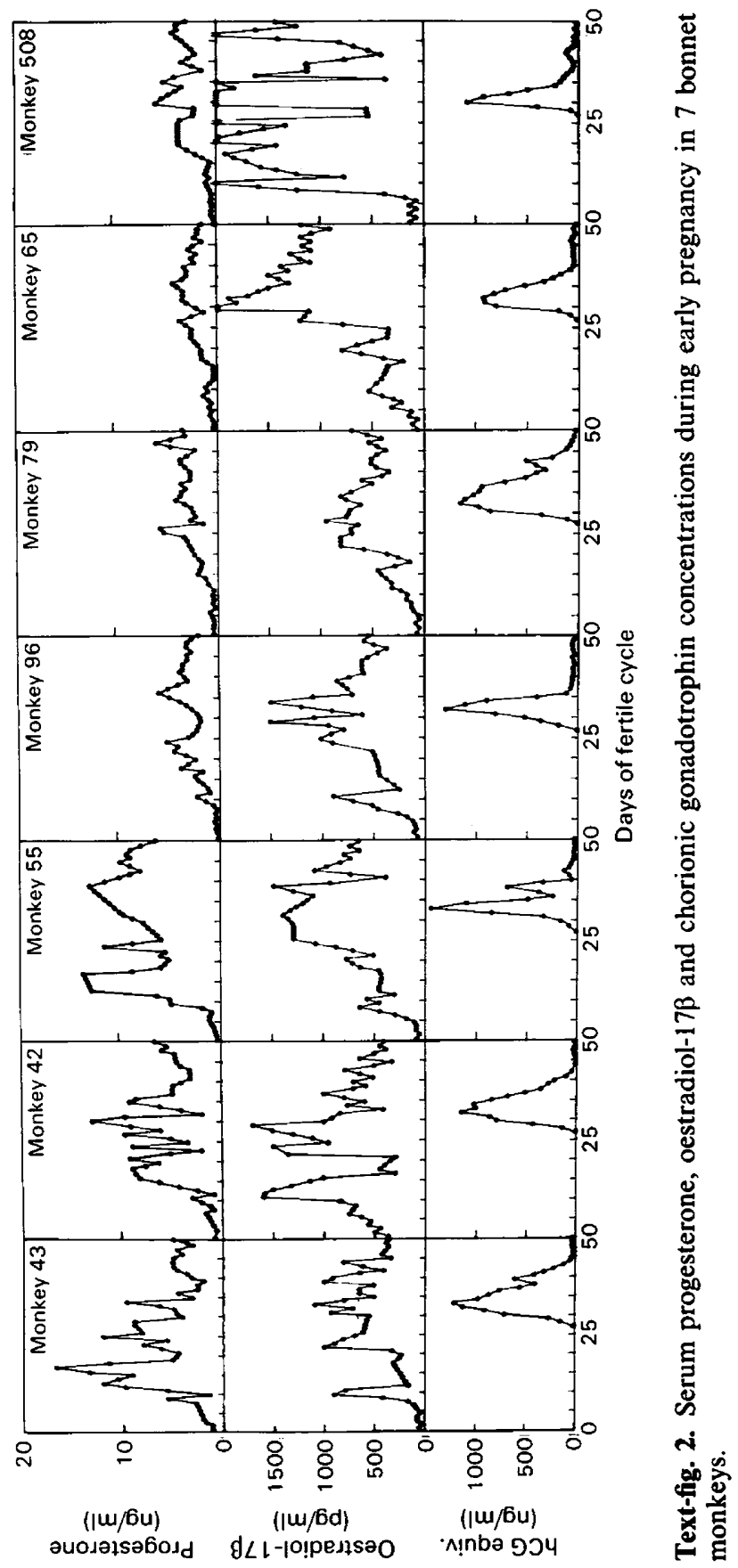


the preovulatory surge of oestradiol-17 $(900-1000 \mathrm{pg} / \mathrm{ml})$ seen around Day 9-10 of cycle, oestradiol-17 levels again rose to peak values by Day 30-31 of the fertile cycle, after which there was a sharp fall. However, the levels remained elevated for the rest of the period studied. There was considerable variation in the absolute values, the peak values on Day 30 ranging from 560 to 3600 $\mathrm{pg} / \mathrm{ml}$ (Text-fig. 2).

Serum progesterone concentrations were measured from Day 1 to Day 50 of the fertile cycle (Text-fig. 2). Assuming that conception occurred between Days 11 and 13, progesterone values increased significantly $(P=0.01-0.025$ between Days 18 and 8$)$ by Day $18(6 \mathrm{ng} / \mathrm{ml})$ and decreased to $4 \mathrm{ng} / \mathrm{ml}$ by Day 20 of the cycle. However, mean serum progesterone concentration was significantly higher $(P=<0.005)$ on Day 23 of a fertile cycle compared to the same day in a nonfertile cycle (mean \pm s.e.m. $5.81 \pm 1.24(n=7)$ and $1.24 \pm 0.13(n=14) \mathrm{ng} / \mathrm{ml})$. Although the peak serum progesterone values ranged between 9 and $18 \mathrm{ng} / \mathrm{ml}$ during pregnancy, lower values did not interfere with the course of pregnancy as all the animals delivered live young.

A composite of the serum progesterone, oestradiol-17 $\beta$ and chorionic gonadotrophin levels from Days 1 to 50 in the 7 monkeys is presented in Text-fig. 3. Despite considerable variation in individual monkeys, the mean level of progesterone was significantly higher from Day 18 onwards and the average levels of progesterone in the pregnant monkeys were at no time lower than $2 \mathrm{ng} / \mathrm{ml}$ after Day 18 of the fertile cycle. Serum oestradiol-17ß levels also remained above $500 \mathrm{pg} / \mathrm{ml}$ after

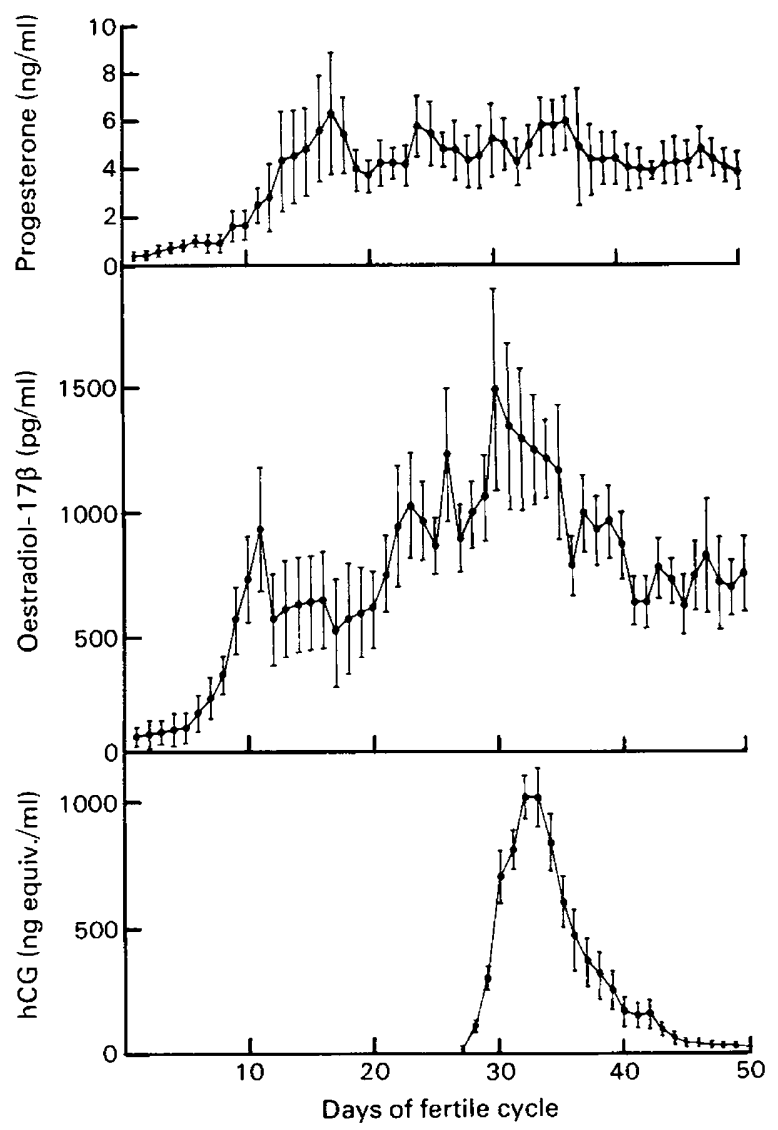

Text-fig. 3. Composite figure showing mean \pm s.e.m. (7 monkeys) concentrations of serum progesterone, oestradiol-17 $\beta$ and chorionic gonadotrophin during early pregnancy in the bonnet monkey. 
Day 10 and showed maximal values by Day 30 of the fertile cycle, which is just before the CG levels reach peak values. While the day-to-day increase of CG values was very rapid, the decline was gradual, reaching very low levels by Day 45 of the fertile cycle.

\section{Discussion}

It is evident from the foregoing that the endocrine profile of the bonnet monkey during the periimplantation period generally resembles that of the rhesus monkey. Of the two major studies on CG levels in the rhesus monkey, Atkinson et al. (1975) used an antiserum which cross-reacted with LH as well as CG from human, gorilla, chimpanzee, orangutan and baboon (Hobson, 1976), while an antiserum which cross-reacted with rhesus monkey and baboon CG was used by Hodgen, Tullner, Vaitukaitis, Ward \& Ross (1974). In the CG assay used in this study, monkey LH, as derived from the pituitary homogenates or the serum of gonadectomized monkeys, showed low cross-reactivity and even this could only be demonstrated by using large volumes of sera $(300-400 \mu \mathrm{l})$. Since $50 \mu \mathrm{l}$ serum from a pregnant monkey (Days 30-35 of a fertile cycle) were adequate to measure bonnet monkey CG, it can be concluded that the assay system did provide a true measure of this CG.

The general profile of CG secretion (duration and concentration) in the bonnet monkey appears to be very similar to that observed in the rhesus monkey. The variation in the day of initial detection of CG could be ascribed to the fact that Day 12 was assumed to be Day 1 of pregnancy although there may be a difference of 2-3 days. The peak values obtained and the day-to-day increment in CG also exhibited a large variation. The CG levels in the bonnet monkey attain maximal values by Day 34-35 of the fertile cycle and this correlates well with the effects of ovine LH antiserum capable of neutralizing both CG and LH; injection before Day 37 of the fertile cycle results in termination of pregnancy (Prahalada et al., 1975; Moudgal, Mukku, Prahalada, Murty \& $\mathrm{Li}, 1978$ ).

It is possible that CG secretion from the blastocyst occurs earlier than Day 28 of the fertile cycle but failure to demonstrate this here could be a function of the sensitivity of the $C G$ assay used. Earlier studies from this laboratory (Mukku \& Moudgal, 1979) suggested that rescue of the corpus luteum in the bonnet monkey must be occurring about Day 23 of the fertile cycle and the progesterone profiles seen in this study between Days 20 and 28 of the fertile cycle lend support to this. The progesterone levels around implantation in many primates studied are indistinguishable from those during the non-fertile cycle, the possible exception being the bonnet monkey and the marmoset (Stabenfeldt \& Hendrickx, 1972; Hendrickx \& Enders, 1980). Both Mukku \& Moudgal (1979) and Hendrickx \& Enders (1980) have observed that even during peri-implantation period the progesterone levels of the fertile bonnet monkey are much higher than in the unmated cyclic monkey at the same time. The results of the present study are essentially in agreement with this. The general pattern of circulating oestradiol- $17 \beta$ concentrations is similar to that reported for the rhesus monkey (Bosu, Johansson \& Gemzell, 1973; Atkinson et al., 1975). In view of the fact that no alteration in circulating oestradiol-17 $\beta$ levels are seen before implantation (Reinius, Fritz \& Knobil, 1973) and implantation takes place normaliy in rhesus monkeys that have been ovariectomized within 6 days of ovulation and treated with progesterone (Meyer, Wolf \& Arslan, 1969), it has been suggested that oestradiol may not play a direct role in implantation in the monkey. However, in view of our present observation that oestradiol-17 $\beta$ levels generally remain elevated (above $500 \mathrm{pg} / \mathrm{ml}$ ) from Day 10 until Day 30 of the fertile cycle, during which time implantation takes place, the role of oestrogen in primate implantation should be re-investigated.

We thank the Family Planning Foundation of India, the Indian Council of Medical Research and the World Health Organization (by way of small supplies programme) for financial aid; Professor C. H. Li, Dr M. R. Sairam, and the Hormone Distribution Section, NIH, for gifts of the hormones used; and $\mathrm{Mr} \mathrm{B}$. Shanmugha Velu for help with blood sampling and maintenance of the monkeys. 


\section{References}

Atkinson, L.E., Hotchkiss, J., Fritz, G.R., Surve, A.H., Neill, J.D. \& Knobil, E. (1975) Circulating levels of steroids and chorionic gonadotropin during pregnancy in the rhesus monkey, with special attention to the rescue of the corpus luteum in early pregnancy. Biol. Reprod. 12, 335-345.

Bosu, W.T.K., Johansson, E.D.B. \& Gemzell, C. (1973) Patterns of circulating oestrone, oestradiol $17-\beta$ and progesterone during pregnancy in the rhesus monkey. Acta endocr., Copenh. 74, 743-755.

Greenwood, F.C., Hunter, W.M. \& Glover, J.S. (1963) The preparation of ${ }^{131}$ I labelled human growth hormone of high specific radioactivity. Biochem. $J$. 89, 114-123.

Hendrickx, A.G. \& Enders, A.C. (1980) Implantation in non-human primates. In Non-human Primate Models for Study of Human Reproduction, pp. 109-115. Ed. T. C. Anand Kumar. S. Karger, Basel.

Hobson, B.M. (1976) Evaluation of the sub-human primate tube test for pregnancy in primates. Lab. Anim. 10, 87-91.

Hodgen, G.D., Tullner, W.W., Vaitukaitis, J.L., Ward, D.N. \& Ross, G.T. (1974) Specific radioimmunoassay of chorionic gonadotrophin during implantation in rhesus monkey. J. clin. Endocr. Metab. 39, 457-464.

Meyer, R.K., Wolf, R.C. \& Arslan, M. (1969) Implantation and maintenance of pregnancy in progesteronetreated ovariectomized monkeys (Macaca mulatta). In Recent Advances in Primatology, vol. 2, pp. 30-35. S. Karger, Basel.

Moudgal, N.R., Mukku, V.R., Prahalada, S., Murty, G.S.R.C. \& Li, C.H. (1978) Passive immunization with an antibody to the $\beta$-subunit of ovine luteinizing hormone as a method of early abortion - a feasibility study in monkeys (Macaca radiata). Fert. Steril. 30, 223-229.
Mukku, V.R. \& Moudgal, N.R. (1979) Regulation of corpus luteum function in the sub-human primate - a study in bonnet monkeys. In Recent Advances in Reproduction and Regulation of Fertility, pp. 135142. Ed. G. P. Talwar. Elsevier/North-Holland, Amsterdam.

Mukku, V.R., Prahalada, S. \& Moudgal, N.R. (1976) Effect of constant light on nycthemeral variations in serum testosterone in male Macaca radiata. Nature, Lond. 260, 778-779.

Murty, G.S.R.C., Sheela Rani, C.S., Moudgal, N.R. \& Prasad, M.R.N. (1979) Effect of passive immunization with specific antiserum to FSH on the spermatogenic process and fertility of adult male bonnet monkey (Macaca radiata). J. Reprod. Fert., Suppl. 26, 147-163.

Prahalada, S., Mukku, V.R., Rao, A.J. \& Moudgal, N.R. (1975) Termination of pregnancy in macaques (Macaca radiata) using monkey antiserum to ovine luteinizing hormone. Contraception 12, 137-147.

Reinius, S., Fritz, G.R. \& Knobil, E. (1973) Ultrastructure and endocrinological correlates of an early implantation site in the rhesus monkey. J. Reprod. Fert. 32, 171-173.

Stabenfeldt, G.H. \& Hendrickx, A.G. (1972) Progesterone levels in the bonnet monkey (Macaca radiata) during the menstrual cycle and pregnancy. Endocrinology 91, 614-619.

Stabenfeldt, G.H. \& Hendrickx, A.G. (1973) Progesterone studies in the Macaca fascicularis. Endocrinology 92, 1296-1300.

Vaitukaitis, J., Robbins, J.B., Nieschlag, E. \& Ross, G.T. (1971) A method for producing specific antisera with small doses of immunogen. J. clin. Endocr. Metab. 33, 988-991. 